\title{
Parametric Analysis of a Turbojet engine with reduced inlet pressure to the compressor
}

\author{
Ujam, A.J. \\ Department of Mechanical and production Engineering Enugu State University of Science and Technology, \\ Enugu, Nigeria
}

\begin{abstract}
Jet engines are required to operate at a higher rpm for the same thrust values in cases such as aircraft landing and military loitering. High rpm reflects higher efficiency with increased pressure ratio. This work is focused on performance charactristics of turbojet with reduced inlet pressure to the compressor engine. A real-time turbojet engine integrating aerothermodynamics of engine components, was developed, together with principles of jet propulsion and inter component volume dynamics represented in 1-D non-linear equations. Specific fuel consumption, specific thrust, component pressure ratios, thermal and propulsive efficiencies are the performance parameters of the engine that were analyzed on the model with reduced inlet pressure for the real-time test cases of desired thrust range. A flow control mechanism that produces a pressure drop across inlet was assumed and the analyses are carried out with reduced compressor inlet pressure for matching thrust. The result of my findings shows that with increase in shaft rpm, pressure and temperature ratio values across the compressorturbine assembly increases. Performance parameters of the engine are analyzed with the increase in compressor pressure ratio and shaft rpm.
\end{abstract}

Keywords: - Turbojet, Specific Thrust, Specific Fuel Consumption, Thermal Efficiency, Propulsive Efficiency

\section{INTRODUCTION}

Jet engines are highly non-linear plants with a complex range of operation described by a flight envelope. Altitude and Mach number defines the operational set points for the engine. The main task for these systems is the production of adequate thrust while maintaining safe and stable operation. Performance requirements for the engines vary according to mission characteristics. Civil aircraft operation requires minimum running and maintenance costs. Military aircraft require maximum available thrust in a minimum response time. However, increasing the efficiency and minimizing running cost by reducing fuel consumption is an important criterion for any jet engine. Even a small percent decrease in fuel consumption translates to a significant saving of running costs over the life of a typical jet engine. Similarly, a slight increase in the efficiency could increase the operational life of the engine.

This work is an approach to analyze the performance of jet engine with an alternative flow control mechanism. The work analyzes the feasibility of a thrust control mechanism by regulating the flow at the engine inlet to increase the engine rpm for the same value. This approach adds value to the design process with the aim of increasing performance levels in the engine operation. A flow control mechanism in the inlet produces a pressure drop across the inlet section and compressor inlet pressure is reduced. Performance characteristics for a TF39 turbojet engine is analyzed with reduced inlet pressure to the compressor and matching thrust. Thermal efficiency of the engine is a function of pressure ratio across the compressor and also isentropic efficiency is integrated to the component pressure ratio with shaft rpm values.

Jet Engine is the gas turbine application for aircraft propulsion. Basic principle in a jet engine is to accelerate a mass of fluid in the direction opposite to motion and thereby propelling the aircraft forward by the thrust generated. Schematic differences between the Turbojets, Turbofans and Turboprop/Turbo shaft Engines are shown in figure 1,2 and 3.

\subsection{Turbojet Engine}




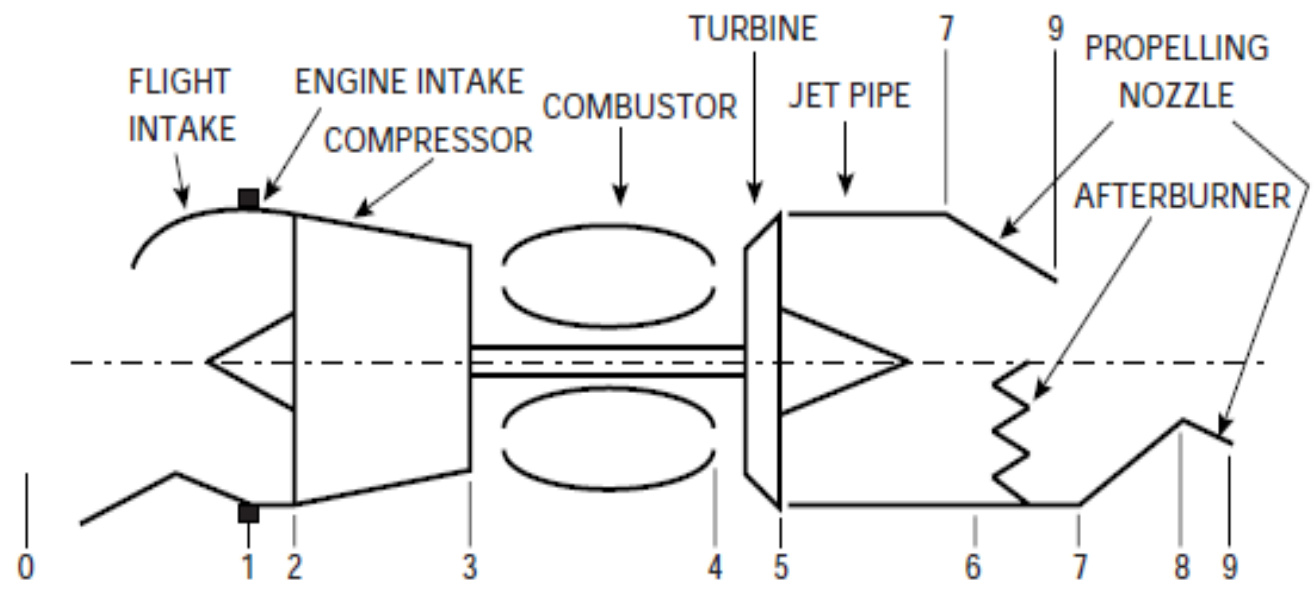

Figure 1: Turbojet Engine Configurations [1]

At point 0 ambient air passes from free stream to the flight intake leading edge at 1 and the air accelerates from free stream if the engine is static, whereas at high flight Mach number it diffuses from the free stream, ram conditions. Usually, it then diffuses at point 2 in the flight intake before passing through the engine intake to the compressor face with a small loss in total pressure. The compressor then increases both the pressure and temperature of the gas. Work input is required to achieve the pressure ratio; the associated temperature rise depends on the efficiency of the compressor. The compressor exit diffuser at point 3 passes the air to the combustor. Here, fuel is injected and burnt to raise exit gas temperature at point 4 . The diffuser and combustor both impose a small total pressure loss. The hot, high pressure gas is then expanded through the turbine where work is extracted to produce shaft power; both temperature and pressure are reduced. The shaft power is that required to drive the compressor and any engine auxiliaries. On leaving the turbine at point 5, the gas is still at a pressure typically at least twice that of ambient. This results from the higher inlet temperature to the turbine. Downstream of the turbine the gas diffuses in the jet pipe at point 6 . This is a short duct that transforms the flow path from annular to a full circle at entry to the propelling nozzle at point 9 . The jet pipe imposes a small total pressure loss. At point 7 afterburner is introduced, an afterburner is a combustor located downstream of the turbine blades and directly upstream of the nozzle, which burns fuel from afterburner-specific fuel injectors. The propelling nozzle is a convergent duct that accelerates the flow to provide the high velocity jet to create the thrust. Engine cooling system uses the relatively cool air from the compression system that bypasses the combustor via air system flow paths to cool the turbine nozzle guide vanes and blades to ensure acceptable metal temperatures at elevated gas temperatures.

For high flight Mach number applications an afterburner is often employed, which offers produces higher thrust from the same configuration. This is also called reheat, and involves burning fuel in an additional combustor downstream of the turbine. Turbojets are quite inefficient compared to other engine types at lower Mach numbers but has dominant role for the supersonic flight modes and military applications.

\subsection{Turbofan Engine}

Turbofans are widely used engines for the modern civil-aircraft propulsion. A turbofan engine is based on the principle that for the same power, a large volume of slower-moving air will produce more thrust than a small volume of fast-moving air. Turbofan engines are of two types: separate jets turbofan and mixed turbofan with afterburner. Figure 2 shows the configuration of the separate jets turbofan above the centre line and mixed turbofan with afterburner below the centre line. 


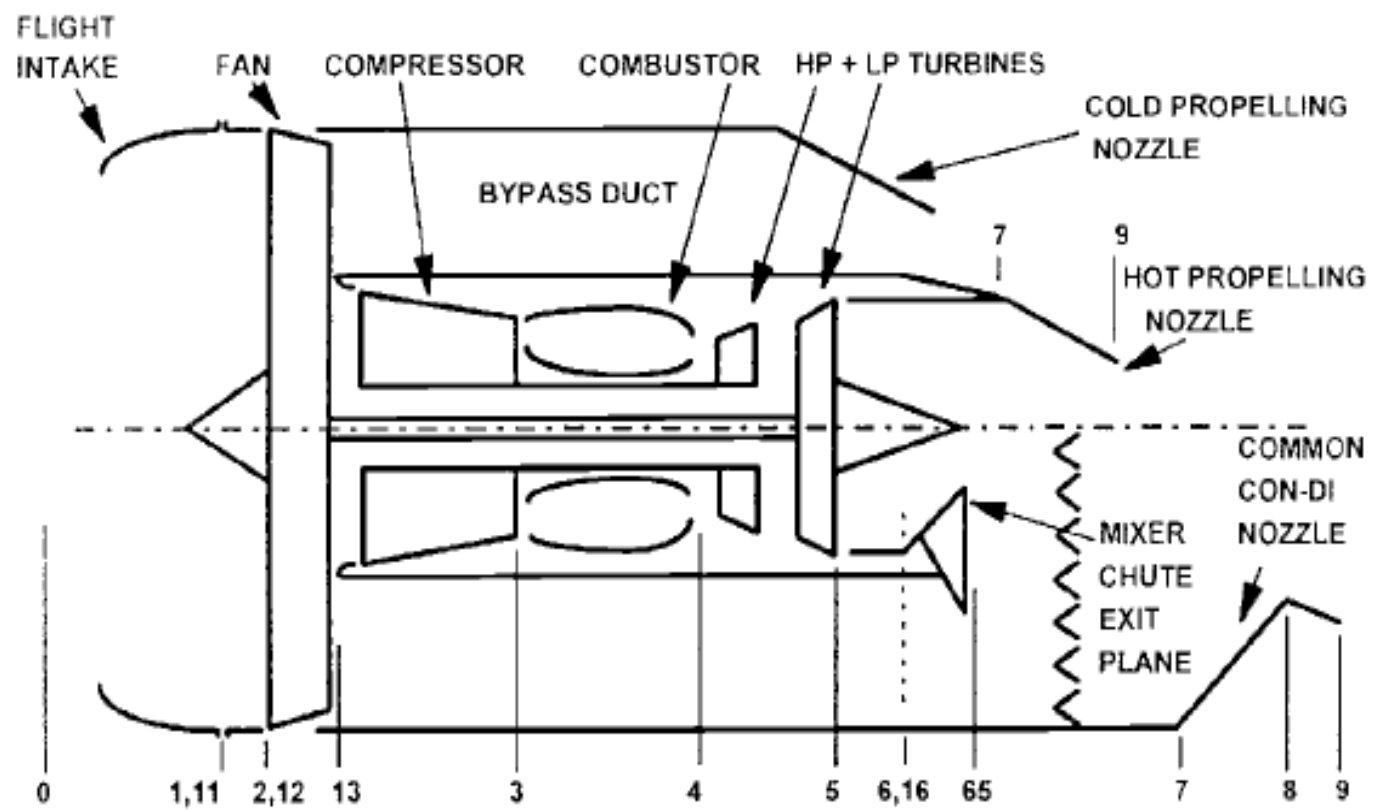

Figure 2: Turbofan Engine Configurations [1]

In the turbofan engine, the first compressor is termed a fan and supplies flow to a bypass as well as a core stream. The core stream is the same as that of a turbojet and provides the hot thrust; however, the core turbines also provide power to compress the fan bypass stream. The bypass stream passes through the bypass duct, incurring a small total pressure loss. It then enters the cold nozzle in the case of separate jets. The total thrust is the sum of those from both the hot and cold nozzles. The purpose of the bypass stream of air is to generate additional thrust with a high mass flow rate than to the low jet velocity, which improves specific fuel consumption (SFC) relative to a pure turbojet. However, this results in lower ratios of engine thrust to frontal area and weight. In the case of the mixed turbofan engine, the core gas and the by-pass air streams are combined in a mixer upstream of a common jet pipe with an afterburner and convergent-divergent nozzle to provide high jet velocities for supersonic flight. It is often also beneficial to mix the two streams for turbofans without afterburners.

\subsection{Turbo Shaft/Turboprop Engines}

Turbo shaft and Turboprop engines have the core turbojet components, power turbine of the turbofan engine without the fan. The main difference is that all the available pressure at entry to the turbine is expanded to ambient to produce shaft power. After diffusion in the exhaust duct, the gas exit velocity is negligible. This results in turbine power substantially greater than that required to drive the compressor, hence excess power drives the load, such as a propeller for a turboprop engine or an electrical generator for a turbo shaft.

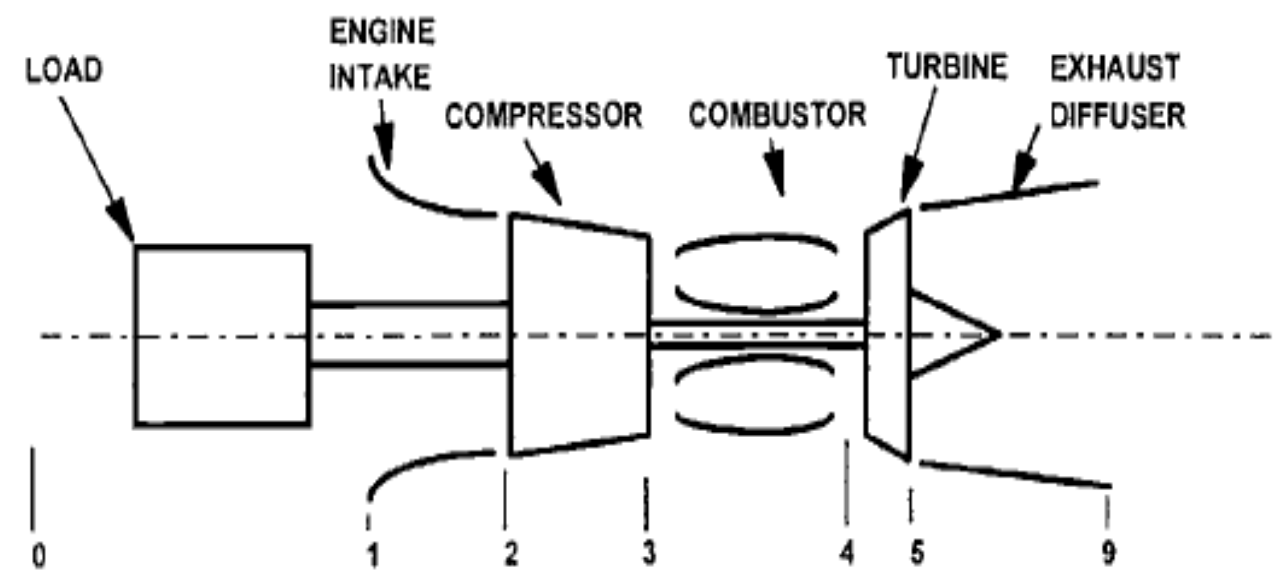

Figure 3: Turbo Shaft Engine Configurations [1] 


\subsection{Ideal Turbojet Cycle}

Temperature-entropy (T-s) diagram of the ideal jet engine cycle is shown in Figure 2.5. The pressure of the air rises slightly as it is decelerated in the diffuser. Then, air is compressed by the compressor. It is mixed with fuel in the combustion chamber, where the mixture is burned at constant pressure. The high-pressure and high-temperature combustion gases partially expand in the turbine, producing enough power to drive the compressor and other auxiliary equipment. Finally, the gases expand in a nozzle to the ambient pressure and leave the aircraft at a high velocity.

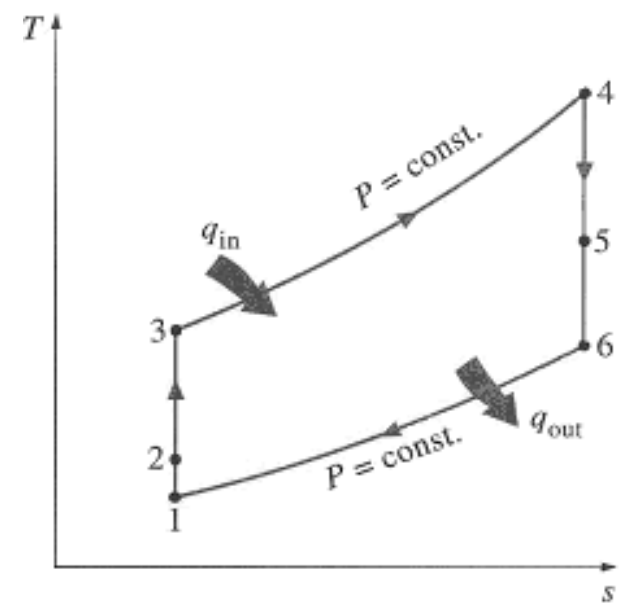

Figure 4: T-S Diagram of the Ideal Turbojet [2]

\section{PARAMETRIC THERMODYNAMICS EQUATIONS}

The performance parameters for an aero-engine are presented here.

\subsection{Specific thrust}

This is the amount of output thrust per unit of mass flow entering the engine. It is particularly important to maximize specific thrust in applications where engine weight or volume is crucial for aircraft that fly at high Mach numbers where the drag per unit frontal area is high. [3]

$$
\text { Specific Thrust, } F_{\mathrm{n}}=\dot{m}\left(\mathrm{v}_{e}-\mathrm{v}_{0}\right)
$$

\subsection{Specific Fuel Consumption(SFC)}

This is the mass of fuel burnt per unit time per unit of output power or thrust. It is important to minimize SFC for applications where the weight and/or cost of the fuel are significant. When specifying the SFC values, it is important to state whether the lower or higher calorific value of the fuel is used. [4]

$$
\text { Specific Fuel Consumption, S.F.C }=\frac{\text { fuel mass flow rate }}{\text { net thrust }}=\frac{\dot{m}_{\mathrm{f}}}{F_{\mathrm{n}}}
$$

\subsection{Thermal Efficiency}

Thermal efficiency for jet engines is defined as the rate of addition of kinetic energy to the air divided by the rate of fuel energy supplied, usually expressed as a percentage. The energy in the jet is proportional to the difference in the squares of jet and flight velocities. Generally thermal efficiency increases as pressure ratio increases and this results in a higher jet velocity for a given energy input. [4]

$$
\text { Thermal Efficiency, } \eta_{t h}=\frac{\text { increase in kinetic energy }}{\text { heat energy added }}=\frac{\mathrm{v}_{e}^{2}-\mathrm{v}_{0}^{2}}{2 * 1000\left(\frac{F}{A}\right) * C_{v}}=\frac{\mathrm{v}_{e}^{2}-\mathrm{v}_{0}^{2}}{2 q_{i n}}
$$

\subsection{Propulsive Efficiency}

Propulsive efficiency for jet engines is defined as the useful propulsive power produced by the engine divided by the rate of kinetic energy addition to the air, again usually expressed as a percentage. The net thrust is proportional to the difference in the jet and flight velocities. Since power is force times velocity, propulsive power is proportional to the flight speed times the difference in the jet and flight velocities. From the formula, propulsive efficiency is improved by low jet velocities, due to lower energy wastage as jet kinetic energy. This requires high pressure ratio and low SOT. However, low jet velocities produce lower thrust output, hence to achieve high propulsive efficiency, as well as a required thrust, high engine mass flow must be coupled with 
low jet velocities. This leads to engines of low specific thrust, which are large and heavy. Turbofan engines are based upon this principle. [4]

$$
\text { Propulsive Efficiency, } \eta_{p}=\frac{2 V_{0}}{V_{e}+V_{0}}
$$

\subsection{Overall Efficiency}

Overall efficiency of a jet engine is the product of the thermal and the propulsive efficiencies of the engine. [4]

$$
\text { Overall Efficiency, } \boldsymbol{\eta}_{o v}=\boldsymbol{\eta}_{t h} * \boldsymbol{\eta}_{p}
$$

\subsection{Standard Atmospheric Parameter Assumptions}

Given the flight altitude, static temperature and static pressure values of the surrounding air (assumed to be perfect gas) can be calculated using ISA model [5]:

$\mathrm{T}_{\mathrm{amb}}=288.15 \mathrm{~K} ; \mathrm{P}_{\mathrm{amb}}=101325 \mathrm{KPa} ; \mathrm{v}=340.294 \mathrm{~m} / \mathrm{s} ; \rho_{=1.225 \mathrm{Kg} / \mathrm{m}^{3}}$

At sea level to $11000 \mathrm{~m}$ altitude. [5]

$\mathrm{T}_{\mathrm{amb}}=288.15-(0.0065 * \mathrm{alt})$

$$
\mathrm{p}_{\mathrm{amb}}=101325 *\left[\left(\frac{\mathrm{T}_{\mathrm{amb}}}{288.15}\right)^{5.2561}\right]
$$

ISA, $11000 \mathrm{~m}$ to $25000 \mathrm{~m}$ Altitude: [6], from equation (6)

$\mathrm{T}_{\mathrm{amb}}=216.69 \mathrm{~K}$

$\mathrm{P}_{\mathrm{amb}}=22632 * \mathrm{e}^{(1.733-0.000157 * \text { alt })}$

With the known value of the flight Mach number, the stagnation values of the temperature and pressure of the ambient air is calculated from the equations, [6]

$$
\begin{aligned}
& \frac{T_{o}}{T_{a m b}}=\left[1+\left(\frac{\gamma-1}{2}\right) * M^{2}\right] \\
& \frac{P_{o}}{P_{a m b}}=\left[\frac{T_{o}}{T}\right]^{\frac{\gamma}{\gamma-1}} *\left[1\left(\frac{\gamma-1}{2}\right) * M^{2}\right]^{\frac{\gamma}{\gamma-1}}
\end{aligned}
$$

\section{COMPONENT BY COMPONENT ANALYSIS}

Figure 5 shows the station numbering of the mathematical model for the engine.

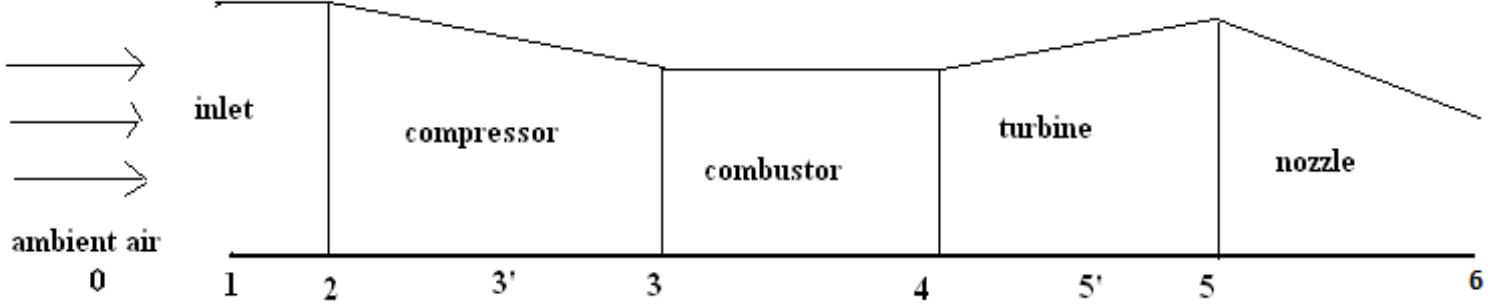

Figure 5: Station Numbering for the Engine Model

A mathematical model, based on the lumped parameter approach is used from the unsteady one dimensional conservation laws described by a set of first-order differential and algebraic equations.

\subsection{Inlet}

Intake diffuser is used to bring the free stream air into the engine. It does no work on the fluid but it guides the fluid flow to the compressor. However, the performance of the inlet is defines by the pressure recovery from the free stream to the engine. An isentropic process is assumed for the air flow in the inlet diffuser. Heat transfer and the friction between the air and the diffuser walls are not considered. The stagnation values of the temperature and pressure at the diffuser exit are calculated from the equations, [7] $\mathrm{T}_{2}=\mathrm{T}_{0}$

$\mathrm{P}_{2}=\eta_{1} * \mathrm{P}_{0}$

Pressure recovery in the diffuser is calculated using the Nigeria Air force standard [7] 


$$
\begin{aligned}
& \eta_{1}=1.0 \text { if } \mathrm{M} \leq 1 \\
& \eta_{1}=1.0-0.075^{*}\left[(\mathrm{M}-1)^{1.35}\right] \text { if } \mathrm{M}>1
\end{aligned}
$$

\section{2Compressor}

The purpose of a compressor is to increase the total pressure of the gas stream to that required by the engine while absorbing the minimum shaft power possible. Temperature of the incoming air also increases with pressure in the compressor. The work done by the compressor on the gas is extracted from the turbine. In the reference engine model, the compressor is an axial compressor with 8 stages.

The final temperature of the compressor is calculated from the equation from the equation. [8]

$$
T_{3^{\prime}}=T_{2}\left(1+\frac{\left(\frac{P_{3}}{P_{2}}\right)^{\frac{\gamma-1}{\gamma}}-1}{\eta_{I s}{ }_{c o m p}}\right)
$$

Where $\gamma_{a}=1.4$ and $\gamma_{g}=1.33$

Work done by the compressor to increase the pressure and temperature of the air can be calculated from the expression. [8]

$$
w_{c}=\dot{m}_{3} * c_{p} *\left(T_{3}-T_{2}\right)
$$

The value for the $\mathbf{C}_{\mathbf{p}}$ in the above expression is calculated at the interpolated temperature value for the compressor given by [8]

$T_{c}=\beta_{c} * T_{3}+\left(1-\beta_{c}\right) * T_{2}$

\subsubsection{Compressor Volume Dynamics}

In the transient process, the compressor is modeled as a mixing volume in which the mass and energy can be accumulated. The gas dynamics associated in the compressor stages are calculated by applying the continuity, energy and Ideal gas equations to the inter component volume between the compressor and the combustor.

\section{Continuity equation: [9]}

$$
\frac{d}{d t}\left(w_{3}\right)=\dot{m}_{3}-\dot{m}_{3}-B l d
$$

Energy equation: [9]

$$
\frac{d}{d t}\left(T_{3}\right)=\frac{1}{w_{3} c_{v}}\left\{\left[\dot{m}_{3} *\left(C_{p} T_{3}-C_{v} T_{3}\right)\right]-\left[\left(\dot{m}_{3}+B l d\right) * R * T_{3}\right]\right\}
$$

Ideal Gas equation: [9]

$$
P_{3}=\frac{w_{3} * R * T_{3}}{V_{3}}
$$

\subsection{Combustor}

Combustion process in this engine model is simplified for the performance calculations and assumed to be instantaneous and complete after the fuel injection to the combustor. However, the actual process of burning the fuel in the combustor is a complex process. After the injection of the fuel into combustor, fuel droplets are engulfed into the air stream and transported to the burning zone. During transportation, the fuel droplets are heated and evaporated due to surrounding air. Then the fuel vapours diffuse and mix with the hot air and then burn at a finite rate. All the factors like mixing of the fuel vapours to the air, combustion rate and combustion efficiency are to be considered for combustor modeling. 


\subsubsection{Pressure Drop in the Combustor}

Unlike the theoretical combustion process where the inlet pressure and outlet pressure of the chamber are equal, there is a pressure drop in the combustion for the actual process. Because of this pressure drop, the gases can flow in the correct direction and mass flow rate through the combustion chamber is calculated. Expression for the pressure drop across the combustor is given by, [10]

$$
\dot{m}_{b}=\dot{m}_{3}=\sqrt{\frac{P_{3}-P_{4}}{R_{b}}}
$$

Where $\mathbf{R}_{\mathbf{b}}$ is the calculated combustor pressure loss coefficient and is calculated from the steady state values of the engine at various speeds.

\subsubsection{Combustor Volume Dynamics}

The combustor is lumped into a single equivalent one dimensional volume. Model is developed from the mathematical expressions of the continuity, energy equation and the ideal gas equation along with the algebraic expression for pressure drop in the combustor.

\section{Continuity equation: [11]}

$$
\frac{d}{d t}\left(w_{4}\right)=\dot{m}_{b}-\dot{m}_{f}-\dot{m}_{4}
$$

Energy balance: [11]

$$
\frac{d}{d t}\left(T_{4}\right)=\frac{1}{w_{4} c_{v b}}\left\{\left[\dot{m}_{3} *\left(C_{p b} T_{b}-C_{v b} T_{4}\right)\right]-\left[\dot{m}_{f} *\left(H V F * \eta_{b}-C_{v b} T_{4}\right)\right]\left[\dot{m}_{4} * R * T_{4}\right]\right\}
$$

\section{Ideal Gas equation: [11]}

$$
P_{4}=\frac{w_{4} * R * T_{4}}{V_{4}}
$$

where $\mathrm{T}_{\mathrm{b}}$ in the above equation is the combustor interpolation constant calculated from the expression: [11] $T_{b}=\beta_{c} * T_{4}+\left(1-\beta_{c}\right) * T_{4}$

The values for the specific heats of the combustor are calculated at the interpolated temperature of the combustor.

\subsection{Turbine}

Turbine is used to extract sufficient energy from the hot gases of the combustor to drive the compressor and other auxiliary power equipment. In the reference engine model, the turbine is an axial turbine with 2 stages. The final temperature of the turbine is calculated from the equation. [11]

$$
T_{5^{\prime}}=T_{4} *\left\{1-\eta_{I s^{-\prime} c o m} *\left[1-\frac{1}{\left(\frac{P_{3}}{P_{2}}\right)^{\frac{\gamma-1}{\gamma}}}\right]\right\}
$$

Work done on the turbine by the hot gases from the combustor can be calculated from the expression: [11]

$$
w_{t}=\dot{m}_{5} * c_{p b} *\left(T_{5}-T_{4}\right)
$$

\subsubsection{Turbine Volume Dynamics}

In the transient process, the turbine is modeled as mixing volume in which the mass and energy can be accumulated. The gas dynamics associated in the turbine stages are calculated by applying the continuity, energy and the Ideal gas equations to the inter component volume between the turbine and the convergent nozzle.

\section{Continuity equation: [11]}

$$
\frac{d}{d t}\left(w_{5}\right)=\dot{m}_{5}-\dot{m}_{5}+B l d
$$


Energy equation: [11]

$\frac{d}{d t}\left(T_{5}\right)=\frac{1}{w_{5} c_{v b}}\left\{\left[\dot{m}_{5} *\left(C_{p b} T_{5^{\prime}}-C_{v} T_{5}\right)\right]-\left[\dot{m}_{5} * R * T_{5}\right]\right\}$

Ideal Gas equation: [11]

$P_{5}=\frac{w_{5} * R * T_{5}}{V_{5}}$

3.5 Nozzle

A convergent nozzle is considered in modeling the engine. The partially expanded gas coming from the turbine at a relatively high pressure is accelerated to a high velocity nozzle. Finally, the gases expand to the ambient pressure and provide the thrust to propel the aircraft. Gas flow in the nozzle is considered to be quasi steady state and so the dynamics in the nozzle are not considered.

Modeling of the convergent nozzle for the engine is based on the following mathematical equations. The mass flow rate through the nozzle depends on two factors: nozzle back-pressure $\mathrm{P}_{\text {back }}$ and the nozzle exit critical pressure $\mathbf{P}_{\text {cr. }}$.

For a specific inlet pressure to the nozzle, there exists a critical back-pressure defined by the expression. [12]

$P_{c r}=\left[\frac{2}{\gamma_{b}+1}\right]^{\frac{\gamma-1}{\gamma}} P_{\text {inlet }}$

Depending on the value of the critical pressure the flow through the nozzle is defined below

Case:1: If the back pressure is greater than the critical pressure value, the flow is subsonic at the exit and the exit pressure is equal to the back pressure. The flow rate, exit velocity and the Thrust produced is calculated with the expressions below

If $\mathrm{P}_{\mathrm{b}}>$ Per,

Exit pressure from the nozzle, [12]

$\mathrm{P}_{\text {exite }}=\mathrm{P}_{0}$

Mass flow rate in the nozzle, [13]

$\dot{m}_{5}=\frac{P_{5}}{\sqrt{R T_{5}}} A_{n z}\left[\frac{P_{e}}{P_{5}}\right]^{\frac{1}{\gamma_{b}}} \sqrt{\frac{2 \gamma_{b}}{\gamma_{b}-1}\left[1-\left(\frac{P_{e}}{P_{5}}\right)\right]^{\frac{\gamma_{b}-1}{\gamma_{b}}}}$

Thrust produced, [13]

Thrust $=c v \dot{m}_{s} \sqrt{2 c_{p} T_{s}\left[1-\left(\frac{P_{e}}{P_{5}}\right)^{\frac{\gamma_{b}-1}{\gamma_{b}}}\right]}$

Jet velocity at the exit of the nozzle, [13]

$V e=\sqrt{\frac{2 \gamma_{b}}{\gamma_{b}-1} R T_{s}\left[1-\left(\frac{P_{e}}{P_{s}}\right)^{\frac{\gamma_{b}-1}{\gamma_{b}}}\right]}$

Case:2: If the back pressure is less than the critical pressure, the flow is sonic or choked at the exit and the exit pressure is equal to the critical pressure. Flow rate, exit velocity, and the Thrust produced is calculated from the expressions below

If $\mathbf{P}_{\mathbf{b}}<\mathbf{P}_{\mathrm{cr}}$

Exit pressure from the nozzle, [13]

$\mathrm{P}_{\text {exite }}=\mathrm{P}_{0}$

Mass flow rate in the nozzle, [13]

$\dot{\boldsymbol{m}}_{5}=\frac{\boldsymbol{P}_{5}}{\sqrt{R T_{5}}} A n z \sqrt{\gamma_{b}\left(\frac{\gamma_{b}}{\gamma_{b}+1}\right)^{\frac{\gamma_{b}}{\gamma_{\mathrm{b}}-1}}}$

Thrust produced, [13]

Thrust $=c_{v} \dot{m}_{5} \sqrt{2 c_{p} T_{5}\left[1-\left(\frac{P_{e}}{P_{5}}\right)^{\frac{\gamma_{b}-1}{\gamma_{b}}}\right]}+A_{n z}\left[P_{c r}-P_{e}\right]$

Jet velocity at the exit of the nozzle, [13] 


$$
V_{e}=\sqrt{\frac{2 \gamma_{b}}{\gamma_{b}-1} R T_{5}\left[1-\left(\frac{P_{e}}{P_{5}}\right)^{\frac{\gamma_{b}-1}{\gamma_{b}}}\right]}
$$

\section{OBSERVATION}

It is observed that the thermal efficiency and fuel flow rate do not have a significant change in lower thrust range of operations. But the engine has the advantage of operating at a higher rpm. This particular application can be applied to any aircraft engine during the time of descent and landing. There will be cases where the aircraft need to gain maximum power from lower thrust range to a maximum thrust range in the minimum time. For an example, consider the case where the aircraft is in its approach to landing. Engine at this point operates in the lower thrust range. At the times like a runway overshoot or a go-around landing case, the engine needs to regain its maximum thrust from the lower range in the minimum amount of time. It is at this particular case, the concept of flow control with reduced inlet pressure has a real-time application. Starting at the time of descent the flow control mechanism to reduce compressor inlet pressure is employed and the efficiency of the engine doesn't change much with this application. But the engine is operated at a higher rpm than normal operation with pressure drop across the inlet. If the engine needs to regain the maximum power for the cases as discussed, it could be achieved faster than the normal operation just by deploying the flow control mechanism.

\section{CONCLUSION}

With the reduction in the inlet pressure, the engine works at a higher rpm to produce the same thrust. This results with increase in the work output but decrease in the net work. Therefore, even with the increase in the compressor pressure ratio and turbine inlet temperature, the engine thermal efficiency goes down in a small proportion. With the higher exit jet velocities, propulsive efficiency of the engine also goes down in a very small proportion. SFC, Thermal and propulsive efficiencies are the major performance parameters for commercial engines. But for military engines, situations demand higher Specific Thrust.

Specific thrust for engine increases with reduced compressor inlet pressure. This is particularly important for the cases of shorter runways and higher climb rate.

Thrust specific fuel consumption value increases with reduced inlet pressure. With increase in the specific fuel consumption value for an engine, the range value for the engine decreases. Thermal and Propulsive efficiencies are also decreasing with reduced inlet pressure. However, if the flow control mechanism is employed for certain time of flight such as landing or takeoff, performance decrease in these actors will not affect the engine operation. It is advantageous to employ the reduced compressor inlet pressure approach if the situation demands engine power to efficiency.

\section{REFERENCES}

[1] http://onlinelibrary.wiley.com. 2013. "Gas Turbine Performance"

[2] http://en.wikibooks.org. 2013. "Jet Propulsion/ Thermodynamic Cycles"

[3] Ronald D. Flack. 2013. "Fundamental of Jet Propulsions and Application" University of Virginia: http://www.scribd.com

[4] Cohen H, Rogers G.F.C and Sravanamuttoo H.I.H: 1987. "Gas Turbine Theory",Longman Group Ltd. $3^{\text {rd }}$ ed. London.

[5] http://www-mdp.eng.cam.ac.uk. 2013. "International Standard Atmosphere ISA"

[6] Nigerian Air Force: 1976. "International Standard Atmosphere (ISA) “

[7] Nigerian Air Force. 2013. https://www.grc.nasa.gov/WWW/k-12/airplane/inleth.html

[8] Changduk Kong, Jongha Park . 2013. "Transient: Performance Simulation of Propulsion System for CRW Type UAV Using SIMULINK”, Dept. of Aerospace Engineering, Chosun University.

[9] George Kopasakis, Joseph W. Connolly, Daniel E. Paxson and Peter Ma: 2008. "Volume Dynamics Propulsion System Modeling for Supersonics Vehicle”, Glenn Research Center, Cleveland, Ohio.

[10] Jayachandran Kamaraj: 2004. "Modeling and Simulation of Single Spool Jet Engine”,. Master Thesis, University of Cincinnati

[11] Kirk J. Gomes, Konstanty C. Masiulaniec and Abdollah A. Afjeh: 2008. "Performance, Usage and Transient Simulation Comparisons Between Modelica (Dymola), MATLAB/Simulink, NPSS and DIGTEM for a Pratt \& Whitney F100 Turbofan Engine". University of Toledo

[12] Philip P. Walsh, Paul Fletcher: 2004. “Gas Turbine Performance”. Blackwell Science.

[13] http://exploration.grc.nasa.gov. 2013. "Rocket Exploration" 